\title{
Non-contraceptive Effects of Subdermal Levonogestrel Implant on Endometriosis Patient : A Case Report
}

\author{
Eka Rusdianto Gunardi, Beryliana Maya Anisa and Yogi Pasidri* \\ Department of Obstetrics and Gynecology, Cipto Mangunkusomo General Hospital, Indonesia \\ *Corresponding author: Yogi Pasidri, Department of Obstetrics and Gynecology, Cipto Mangunkusomo General Hospital, Faculty of \\ Medicine Indonesia University, Emerald Town House AG/01 Bintaro Sector 9, South Tangerang, Banten, Indonesia. \\ To Cite This Article: Eka Rusdianto Gunardi, Beryliana Maya Anisa, Yogi Pasidri, Non-contraceptive Effects of Subdermal Levonogestrel Implant \\ on Endometriosis Patient : A Case Report. Am J Biomed Sci \& Res. 2021 - 11(4). AJBSR.MS.ID.001659. DOI: 10.34297/AJBSR.2021.11.001659.
}

Received: 䟧 January 08, 2021; Published: 㘹 January 20, 2021

\begin{abstract}
Introduction: Endometriosis is characterized as the presence of ectopic endometrial gland outside the uterus. Levonorgestrel (LNG) subdermal implant is a reversible contraception with high effectivity. we report a case of endometrioma with significant pain reduction following insertion of LNG implant.

Case Report: 38 years-old patients with bilateral endometrial cyst. Patient complained of pain in left lower abdomen during menstruation with VAS 7-8. Patient had undergone surgery to remove the right endometrial cyst, however, follow up ultrasonography examination 5 months following surgery showed recurrence of cyst on the right ovary. We treated the patient with levonogestrel subdermal implant.

Discussion: Studies showed high effectiveness of ENG implant in improving pain symptoms, however there is still limited data regarding LNG implant effectiveness. At 1 month follow up examination following LNG implant insertion, there was significant pain reduction to VAS 3 . At 3 month follow up, patient reported pain with VAS 3 and no difficulties in doing daily tasks. We conclude that LNG implant is as effective as other progestin only therapy in reducing pain symptom.

Conclusion: Levonorgestrel subdermal implant have high effectiveness in reducing pain in patient with endometrioma.
\end{abstract}

Keywords: levonorgestrel; Implant; Endometrial cyst; Pain

\section{Introduction}

Endometriosis is characterized as the presence of ectopic endometrial gland outside the uterus. It affects around 10-15\% women of reproductive age. To date, there is still no definitive etiology of endometriosis. There are a few hypothesis regarding the mechanism of this disease, one of which is the retrograde menstruation. Retrograde flow of menstrual bleeding is thought to cause seeding of endometrial gland outside the uterus. Other factors such as hormonal, inflammatory, and immunologic milieu may play an important part on lesion location and progression [1]. Endometriosis on the ovary is called endometrioma or chocolate cyst, due to its dark brown appearance inside the cyst. Around 17$44 \%$ patients with endometriosis develop endometrioma. During menstruation, endometrial gland inside the ovary bleeds causing hematoma. Unlike normal hematoma which observed during normal ovulation, endometrioma contains more fibrous tissue. This condition commonly cause adhesion to the surrounding area and cause significant pain [2].
Levonorgestrel (LNG) subdermal implant is a reversible contraception with high effectivity. It is implanted under the skin of the upper arm. This contraception works by releasing hormone to the circulation at a constant rate. Cumulative pregnancy rate of LNG implant at 5 years is less than 2 pregnancies per 100 women [3]. LNG implant works by disrupting follicular growth and ovulatory process, causing anovulation and insufficient luteal function. Commonly it causes changes in menstrual bleeding patient. Normal fertility returns rapidly after removal of LNG implant [4]. In this literature, we report a case of endometrioma with significant pain reduction following insertion of LNG implant.

\section{Case Report}

A 38-year-old patient presented to the gynecology clinic with chief complaint of pain in the left lower abdomen during menstruation for 8 months before admission. Pain intensity was at visual analog scale (VAS) 3-4 but had increased incredibly to VAS 
7-8 these past 5 months. Pain especially felt during menstruation and defecation. There was no pain during urination or sexual intercourse. Patient had been diagnosed with bilateral endometrial cysts and underwent surgery to remove right endometrial cyst 5 months prior in previous hospital. Cytology examination showed result appropriate to hemorrhage cyst with no malignant cell. Patient had her first menstruation at 14 years old and had regular menstruation cycle. Patient has been married and blessed with 2 children age 15 and 10 years old. History of using any contraception method was denied. Patient appeared alert with normotensive blood pressure $(104 / 70 \mathrm{mmHg})$, heart rate $81 \mathrm{x} /$ minute, respiration rate $20 \mathrm{x} /$ minute, and temperature $36 \mathrm{oC}$. Body mass index was at 26,37 $\mathrm{kg} / \mathrm{m} 2$. There was unremarkable finding on general examination. Cervix portio was smooth, closed, with no fluor, fluxus, or active bleeding. There was a cystic mass sizing $6 \mathrm{~cm}$ in diameter palpated at posterior uterus. Ultrasonography examination following admission showed diffuse adenomyosis, bilateral endometrial cyst (right: $68 \times 64 \times 70 \mathrm{~mm}$, left: $52 \times 51 \times 47 \mathrm{~mm}$ ), and internal genital adhesion. Laboratory examination showed E2 level at $105 \mathrm{pg} /$ $\mathrm{mL}$ and CA 125 marker at 44,9 $\mathrm{U} / \mathrm{mL}$. Long term medication was decided as treatment plan. Patient chose subdermal implant as her contraceptive method.

\section{Discussion}

Endometrioma is the most common form of endometriosis. The exact etiology of this disease is still unknown, however there are a few hypothesis regarding its pathogenesis. Retrograde menstrual flow in addition to hormonal, inflammatory, and immunologic factor are believed to play part in development of this lesion. Retrograde flow of menstrual blood causes adhesion of endometrial gland on the ovarian surface. During every menstruation cycle, endometrial gland forms blood filled cyst on the ovarian surface. Cyst will develop steadily by invaginating ovarian cortex. Endometrioma cyst is not surrounded by thick capsule and usually spreads to other pelvic organ. Studies showed there is an association between endometrioma and ovarian cancer. Malignant transformation of endometrioma cyst was observed in 0,7-1\% patient [5].

Treatment of endometrioma is consists of medical and surgical therapy. The choice of treatment is decided based upon targeted symptoms and fertility restoration. Pain is the most common symptom of endometrioma. It occurs due to chronic inflammation of the pelvic and peritoneum. Around $60-70 \%$ patients present with chief complaint of dysmenorrhea. Hormonal agents can help reduce pain by creating hypoestrogenic, hyperandrogenic, or hyperprogestogenic condition that suppresses proliferation of endometrial cell [6]. Endometriosis is an estrogen-dependent disease so progesterone-only contraception method is more preferable. Treatment of choice include oral desogestrel or oral dienogest, DMPA, ENG implant, and LNG IUS [7].
Since endometriosis cause chronic inflammation, a nonsteroidal anti-inflammatory agent can be used alone or in combination with hormonal therapy. COC is the first line treatment for endometrioma due to its effectiveness and low cost. Some studies showed that treatment with $\mathrm{COC}$ cause reduction of endometrioma size. Progestin derivative is also considered as first line treatment. Second line treatment includes GnRH analogues and aromatase inhibitors. If pain persists despite medical therapy, lesion resection or ablation and adhesion lysis should be performed by operation. However, it should be noted that endometriosis has high recurrence rate. The rate of re-operation at 2,5 , and 7 years follow up are $21 \%$, $47 \%$, and $55 \%$ respectively. Studies showed that neither medical therapy nor surgery is more preferred to improve pregnancy rates. Currently there is no trial comparing the effectiveness of medical and surgical therapy in reducing endometriosis-associated pain, but studies of each modality showed promising result. It can be concluded that both treatment are equally effective in reducing pain and treatment decision should be individualized based on patient symptom and plan for future pregnancy [6].

There are three types of subdermal progestin implant, a single ENG rod, single LNG rod, and LNG two rod system. Single LNG rod has been presented in Indonesia, this kind of implant has more advantage since it is easier to be used and removed. ENG rod has 3 years lifespan and more commonly used in developed countries. Meanwhile LNG rod has 5 years lifespan and mainly used in developing countries due to its lower cost. The exact mechanism of progestin in reducing endometriosis related pain is still not clearly understood. Pain from endometriosis may rise from active bleeding from endometric lesion, overexpression of growth factors and proinflammatory cytokines, and irritation of pelvic nerves. Progestin induced endometrial atrophy, anovulation, and inhibit anti-inflammatory actions. It also reduces $\mathrm{GnRH}$ releasing frequency causing reduce secretion of FSH and LH. Long term progestin used will suppress steroidogenesis from the ovary with anovulation and low ovarian steroid levels. The hypoestrogenic and hypergestagenic state will cause decidual transformation in both eutopic and ectopic endometrium [8]. Study on 50 women with symptomatic endometriosis showed that ENG implant reduce pain severity and menstrual symptoms. Dysmenorrhea visual analogue scale score (VAS) kept decreasing from 7,08 + 2,09 at baseline to $3,72+2,04$ at 4 th week then $0,84+1,67$ at 12 th week [9]. Another study comparing effectiveness of ENG implant and DMPA on 41 subjects with symptomatic dysmenorrheal showed that pain reduction occurred in both groups. At 6 months follow up, there were $68 \%$ reduction of pain in ENG implant group and 53\% in DMPA group [10]. Study comparing effectiveness of ENG implant and LNG IUS showed similar result [11]. Data regarding use of LNG subdermal implant as endometriosis treatment is still limited [12]. 
In our case, patient had undergone surgery to remove right endometrial cyst. However, follow up ultrasonography examination 5 months after surgery showed recurrence of endometrial cyst. There was also no improvement of pain following surgery. With this in mind, we chose for long term medication therapy to reduce symptoms. Patient was educated about various hormonal agent available for treatment. Patient chose subdermal implant as therapy due to its long lifespan and high effectiveness in preventing pregnancy. LNG subdermal implant is available in Indonesia and provided for free. At 1 month after insertion follow up examination following LNG implant insertion, there was significant pain reduction from 7 to VAS 3. Same as 2 and 3 month follow up, patient presents during menstruation with pain level at VAS 3 and no difficulties in doing daily tasks. We report the effectiveness of LNG subdermal implant in reducing pain in patient with endometrioma. We plan to do further research involving more subjects to observe the mechanism of pain relief after LNG subdermal implant insertion in patient with endometrial cyst (Table 1).

Table 1: Hormonal agents used to reduce pain in endometriosis patient $[5,7]$.

\begin{tabular}{|c|c|c|}
\hline Agent & Mechanism of action & Side effect \\
\hline Progesterone-releasing IUS & $\begin{array}{c}\text { Endometrial atrophy and inflammation response } \cdot \text { Increases viscosity of cervical } \\
\text { mucous } \cdot \text { Reduction in local angiogenesis, innervations, and pelvic vascular con- } \\
\text { gestion } \cdot \text { Increase lesion apoptosis }\end{array}$ & $\begin{array}{l}\text { Mood changes, acne, breast } \\
\text { tenderness, headache }\end{array}$ \\
\hline Subdermal progesterone implant & $\begin{array}{l}\text { ENG implant } \cdot \text { Prevent surge of luteinizing hormone causing ovarian follicular } \\
\text { development without ovulation LNG implant } \cdot \text { Disrupts follicular growth and } \\
\text { ovulatory process causing anovulation and insufficient luteal function }\end{array}$ & Amenorrhea, spotting \\
\hline $\begin{array}{l}\text { Depot medroxyprogesteron } \\
\text { acetate }\end{array}$ & - Suppress endometrial cell proliferation · Enhance endometrial cell apoptosis & $\begin{array}{l}\text { Decreases bone density, } \\
\text { delayed return of fertility, } \\
\text { menstrual irregularities }\end{array}$ \\
\hline $\begin{array}{l}\text { Combined estrogen/progester- } \\
\text { one contraceptives (COC) }\end{array}$ & - Endometrial tissue decidualization followed by atrophy & $\begin{array}{l}\text { Headache, nausea, breast } \\
\text { tenderness }\end{array}$ \\
\hline GnRH analogs & $\begin{array}{l}\text { - Endometrial atrophy due to gonadotropin suppression followed by hypoestro- } \\
\text { genic condition }\end{array}$ & Decrease bone density \\
\hline Aromatase inhibitor & - Inhibit conversion of androgen to estrogen & $\begin{array}{l}\text { Stimulation of ovariaum in } \\
\text { pre-menopausal women }\end{array}$ \\
\hline
\end{tabular}

\section{Conclusion}

Levonorgestrel subdermal implant have high effectiveness in reducing pain in patient with endometrioma and make patient has no difficulties in doing daily tasks.

\section{Acknowledgements}

The authors thank to Department of Obstetrics and Gynecology, Faculty of Medicine University of Indonesia for support this case report.

\section{Conflict of Interest}

The authors declare no conflict of interest.

\section{References}

1. Parasar P, Ozcan P, Terry KL (2017) Endometriosis: epidemiology, diagnosis, and clinical management. Curr Obstet Gynecol Rep 6(1): 3441.

2. Hoyle AT, Puckett Y (2020) Endometrioma [Internet]. USA: NCBI Stat Pearls.

3. Coukell AJ, Balfour JA (1998) Levonorgestrel subdermal implants. A review of contraceptive efficacy and acceptability. Drugs 55(6): 861-867.

4. Weisberg E, Fraser IS (2015) Contraception and endometriosis: challenges, efficacy, and therapeutic importance. Open Access J Contracept 6: 105-115.
5. Kaponis A, Taniguchi F, Azuma Y, Deura I, Vitsas C, et al. (2015) Current treatment of endometrioma. Obstet GynecolSurv 70(3): 183-195.

6. Carpinello OJ, Sundheimer LW, Alford CE, Taylor RN, Decherney AH (2020) Endometriosis [Internet]. USA: NCBI Endo text.

7. Weisberg E, Fraser IS (2015) Contraception and endometriosis: challenges, efficacy, and therapeutic importance. Open Access J Contracept 6: 105-115.

8. Gezer A, Oral E (2015) Progestin therapy in endometriosis. Women's Health 11(5): 642-652.

9. Ponpuckdee J, Taneepanichskul S (2005) The effects of implanon in the symptomatic treatment of endometriosis. J Med Assoc Thai 88 Suppl 2: S7-S10.

10. Walch K, Unfried G, Huber J, Kurz C, van Trotsenburg M, et al. (2008) Implanon versus medroxyprogesteron acetate: effects on pain scores in patients with symptomatic endometriosis - - a pilot study.

11. Margatho D, Carvalho NM, Buhamondes L (2020) Endometriosisassociated pain scores and biomarkes in users of the etonogestrelreleasing subdermal implant or the 52-mg levonorgestrel-releasing intrauterine system for up to 24 months. Eur J Contracept Reprod Health Care 25(2): 133-140.

12. Gunardi ER, Khusen D (2019) New Single Rod Implant Innovation in Indonesia. Am J Biomed Sci \& Res. 